\title{
Fracture behaviour of a self-healing microcapsule-loaded epoxy system
}

\author{
J. Lee ${ }^{1 *}$, D. Bhattacharyya ${ }^{1}$, M. Q. Zhang ${ }^{2}$, Y. C. Yuan ${ }^{2}$ \\ ${ }^{1}$ Centre for Advanced Composite Materials, Department of Mechanical Engineering, The University of Auckland, Private \\ Bag 92019, Auckland 1142, New Zealand \\ ${ }^{2}$ Key Laboratory for Polymeric Composite and Functional Materials of Ministry of Education, Materials Science Institute, \\ Zhongshan University, Guangzhou 510275, PR China
}

Received 21 July 2010; accepted in revised form 14 December 2010

\begin{abstract}
The effect of temperature on the fracture behaviour of a microcapsule-loaded epoxy matrix was investigated. Microencapsulated epoxy and mercaptan-derivative healing agents were incorporated into an epoxy matrix to produce a polymer composite capable of self-healing. Maximum fracture loads were measured using the double-torsion method. Thermal aging at 55 and $110^{\circ} \mathrm{C}$ for 17 hours [hrs] was applied to heal the pre-cracked samples. The addition of microcapsules appeared to increase significantly the load carrying capacity of the epoxy after healing. Once healed, the composites achieved as much as $93-171 \%$ of its virgin maximum fracture load at 18,55 and $110^{\circ} \mathrm{C}$. The fracture behavior of the microcapsule-loaded epoxy matrix was influenced by the healing temperature. The high self-healing efficiency may be attributed to the result of the subsurface micro-crack pinning or deviation, and to a stronger microencapsulated epoxy and mercaptanderivative binder than that of the bulk epoxy. The results show that the healing temperature has a significant effect on recovery of load transferring capability after fracture.
\end{abstract}

Keywords: fracture and fatigue, polymer composites, smart polymers, self-healing, microcapsules

\section{Introduction}

Polymer materials often experience micro-cracks during their service. Self-healing polymeric materials have the built-in capability to substantially recover their load transferring ability after damage. This field of self-healing materials is a relatively new one, beginning in the early 1990s, with the majority of the research occurring in the past decade $[1,2]$. The ring-opening metathesis polymerization of dicyclopentadiene (DCPD) [3, 4], addition and ionic polymerization of epoxy [5], condensation polymerization of polysiloxane [6], organic solvents [7] and isocyanates [8], have been reported for automatically repairing cracks in polymers at room temperature.
Several researchers $[5,9-11]$ have successfully measured fatigue-crack propagation in epoxy resins. Brown and coworkers $[5,9]$ investigated the effect of embedded urea-formaldehyde (UF) microcapsules on the monotonic fracture properties of a selfhealing epoxy. In addition to providing an efficient mechanism for self-healing, the presence of liquidfilled microcapsules increased the virgin monotonic-fracture toughness of epoxy by up to $127 \%$. The increased toughening was correlated with a change in the fracture plane morphology from mirror-like to hackle markings with subsurface microcracking. The addition of microcapsules to an epoxy matrix significantly increased the resistance to crack growth under dynamic loading conditions.

\footnotetext{
${ }^{*}$ Corresponding author, e-mail: jim.lee@auckland.ac.nz
} (c) BME-PT 
Caruso et al. [7] reported for solvent-based selfhealing of epoxy materials an autonomic system yielding complete recovery of fracture toughness after crack propagation. Kamphaus et al. [12] used $\mathrm{WCl}_{6}$ as a catalyst precursor for the ring-opening metathesis polymerization of exo-dicyclopentadiene in self-healing epoxy applications. Li et al. [13] have reported that the diameter of the poly (melamine-formaldehyde) (PMF) microcapsules containing DCPD has a significant influence on the self-healing efficiency.

In this work, microencapsulated epoxy and mercaptan-derivative were incorporated into epoxy resins. The fracture behavior of microcapsules-loaded epoxy matrix was investigated for the effect of temperature. It is found that the suitable healing temperature has a significant effect on the healing of the microcapsule-loaded epoxy matrix, thereby influencing the fracture behavior.

\section{Experimental}

\subsection{Materials and sample preparation}

Two types of epoxy resin were employed. One was diglycidyl ether of bisphenol A (ECS epoxy and ECS winter hardener, Uroxsys Ltd., East Tamaki, New Zealand) acting as the matrix polymer, and the other was diglycidyl tetrahydro-o-phthalate (DTHP, Jindong Chemical Plant, Tianjin, China) with epoxide equivalence weight of $0.65 \mathrm{~mol}(100 \mathrm{~g})^{-1}$, density of $1.24 \mathrm{~g} \cdot \mathrm{ml}^{-1}$ at $20^{\circ} \mathrm{C}$, and viscosity of $0.36 \mathrm{~Pa} \cdot \mathrm{s}$ at $25^{\circ} \mathrm{C}$ as the polymerizable component of the healing agent. Accordingly, two types of curing agent were used. They are diethylenetriamine (DETA) supplied by Shanghai Medical Group Reagent Co. (Shanghai, China) working for pentaerythritol tetrakis (3-mercaptopropionate) (PETMP) with a boiling point of $275^{\circ} \mathrm{C}$ at $1 \mathrm{mmHg}$, density of $1.28 \mathrm{~g} \cdot \mathrm{ml}^{-1}$ at $20^{\circ} \mathrm{C}$, and hydrosulfide group content of $26.55 \%$, purchased from Fluka Chemie AG (Buchs, Switzerland). The catalyst benzyl dimethylamine (BDMA) with boiling a point of $183.5^{\circ} \mathrm{C}$ was purchased from Shanghai Medical Group Reagent Co. (Shanghai, China).

DTHP ( $400.0 \mathrm{~g}$ ) was added to a $2 \mathrm{wt} \%$ aqueous solution of sodium styrene-maleate copolymer $(1200 \mathrm{ml})$. The mixture was vigorously stirred for 5 min and then a few drops of 1-octanol were added to eliminate surface bubbles of the epoxy emulsion. The prepolymer of melamine $(62.5 \mathrm{~g})$ and $37 \%$ formaldehyde $(135.5 \mathrm{~g})$ was synthesized at $70^{\circ} \mathrm{C}$ for $30 \mathrm{~min}$ and $\mathrm{pH}$ value of the solution was kept at about $9-10$ by adding triethanolamine. Subsequently, the prepolymer solution was added to the above epoxy emulsion at $50^{\circ} \mathrm{C}$ with continuous agitation for $1 \mathrm{hr}$ while $\mathrm{pH}$ value of the system was kept at about 3 by adding citric acid. Eventually, the reaction mixture was cooled down to room temperature and the deposit of microcapsules was separated through a Buchner funnel, rinsed with deionized water and vacuum dried. The microcapsules containing the hardener were prepared in two steps. Firstly, mercaptan-derivative was microencapsulated in a similar way as that adopted in making epoxy-loaded microcapsules. Then, the microcapsules were uniformly dispersed into catalyst solution (BDMP) at $40^{\circ} \mathrm{C}$ for a certain time $(0.5-$ $24 \mathrm{hrs}$ ), filtrated, rinsed with ethyl ether and dried at room temperature.

The unfilled epoxy specimens were produced through mixing 4.55 parts Uroxsys ECS resin with 1 part hardener, while the self-healing epoxy composites were prepared by mixing $5 \%$ of the microcapsules containing epoxy and its hardener. Either the unfilled epoxy or the filled version was poured into a closed silicone rubber mold, degassed and cured for $24 \mathrm{hrs}$ at room temperature.

\subsection{Fracture test}

All the tests were conducted in an Instron 1186 mechanical testing machine (Instron, Norwood, MA, USA) to determine extension and maximum load using the three-point bending configuration. Steel devices were fabricated to fix test specimens for the double-torsion test. Prior to testing, a notch was molded and then sharpened by tapping a fresh razor blade in to the material. 3-5 samples were tested for each condition. The samples were cut to $60 \mathrm{~mm} \times 100 \mathrm{~mm}$ size with $10 \mathrm{~mm}$ notch and side

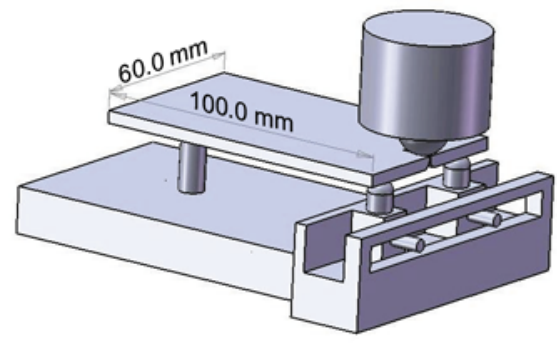

Figure 1. An illustration of the sample loading configuration 
grooves along the centreline of the sample. Figure 1 illustrates the basic geometry of the experimental setup. For fracture tests a pin loading and constant displacement rate condition with $0.2 \mathrm{~mm} / \mathrm{min}$ were used until the crack length was $\sim 2 \mathrm{~mm}$. The above samples were unloaded, healed and tested again after $17 \mathrm{hrs}$ from initial fracture event at 18,55 or $110^{\circ} \mathrm{C}$. Healing efficiencies were determined by comparing the healed peak loads to the virgin peak loads.

\subsection{Characterization}

\subsubsection{Optical images and scanning electron microscope (SEM)}

The appearance of the microcapsules was observed by optical microscope Leica IC3D (Leica Mikrosysteme Vertrieb GmbH, Wetzlar, Germany). The surface morphology of samples was examined by scanning electron microscopy (XL30 ESEM-FEG, Philips, FEI Company, Hillsboro, Oregon, USA). Microcapsules were mounted on a conductive stage. Samples were sputtered with a thin layer $(10 \mathrm{~nm})$ of gold-palladium to reduce charging.

\subsubsection{Size}

The particle size distribution was examined using a Malvern Mastersizer 2000 Ver. 5.54 (Malvern, UK). The particle refractive index parameter was 1.58. The technique is based around the principle that particles passing through a laser beam will scatter light at an angle that is directly related to their size.

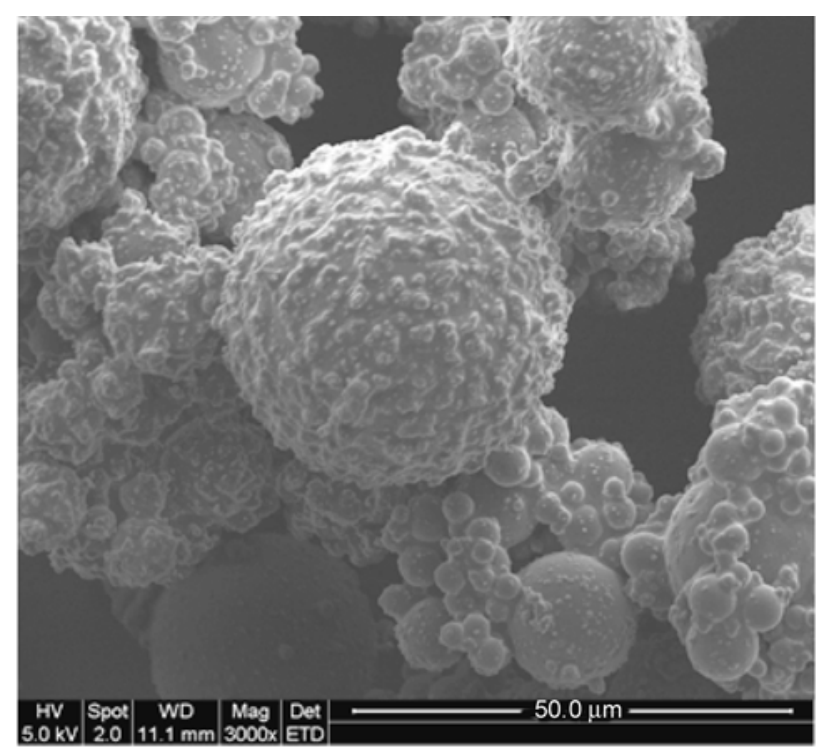

a)

\subsubsection{DSC}

Differential scanning calorimetry (DSC) analysis (TA Q1000 calorimeter, TA Instruments, New Castle, DE, USA) was used to investigate the reactivity of the prepared capsules. Small amounts of samples (5-10 mg) were heated from -20 to $140^{\circ} \mathrm{C}$ at a rate of $5^{\circ} \mathrm{C} / \mathrm{min}$ in a $\mathrm{N}_{2}$ environment.

\subsubsection{FTIR}

Fourier-transform infrared (FTIR) spectra were obtained by Atlas FTIR spectrometer to identify the chemical structure of the specimens, which were prepared by grinding the samples with potassium bromide $(\mathrm{KBr})$ or by appending the samples to a diamond using an Attenuated Total Reflectance (ATR) method.

\section{Results and discussion}

\subsection{Microstructure and particle size distribution of microcapsules}

Figure 2 shows the SEM micrograph of microcapsules. The SEM image of Figure $2 b$ was taken from the surface of a microcapsule-loaded epoxy. The surface of microcapsules is rough, and it may be composed of PMF nanoparticles protruding from the surface [15]. The protuberant nanoparticles can increase the surface area of microcapsules and enhance surface adhesion. Furthermore, the microcapsules can form hydrogen bonding with the matrix due to the presence of polar groups (amine and hydroxyl) on their melamine-formaldehyde

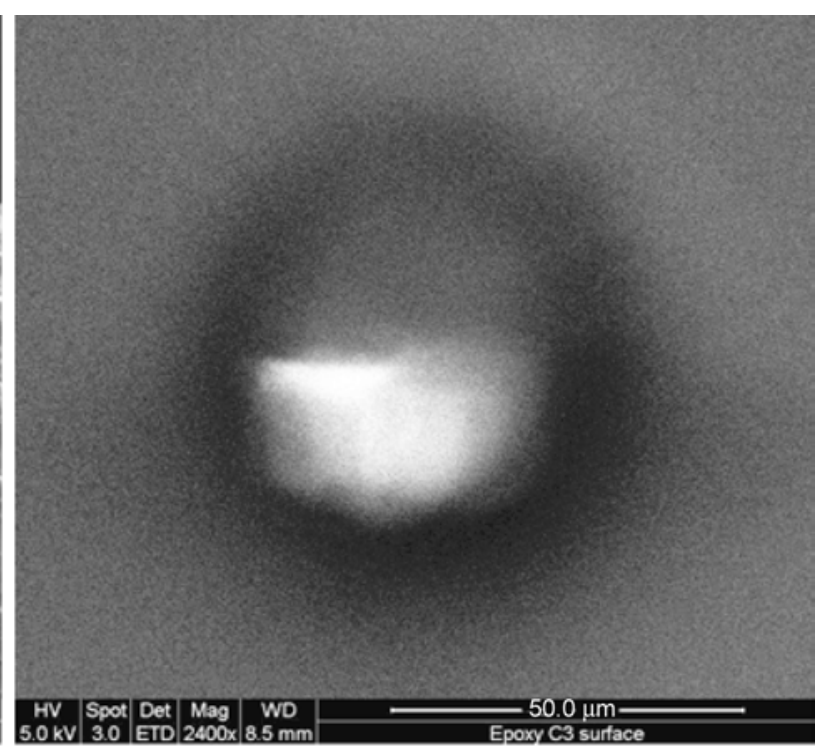

b)

Figure 2. SEM micrographs of epoxy-loaded microcapsules a); the surface of a micro-capsule-loaded epoxy b) 


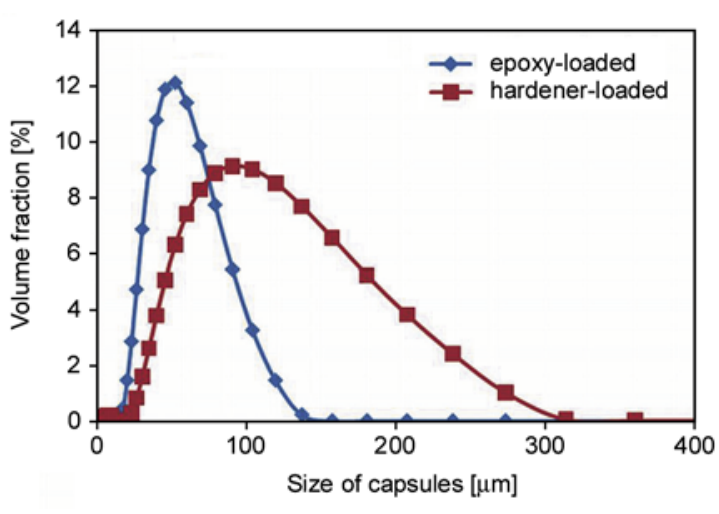

Figure 3. Size distribution of microcapsules: Epoxy- and Hardener-loaded

shells. In Figure $2 b$ it is evident that there is a healant inside the microcapsule. Figure 3 shows the size distribution of microcapsules with epoxy and hardener. The microcapsule size was in a wide range of 10-150 (A) and 20-300 (B) $\mu \mathrm{m}$. The reason is that in the region of flow away from the propeller during the preparation of microcapsules, many larger microeddies exist, and in the vicinity of the propeller, many smaller microeddies exist, which result in a wider length scale [16]. In this study, the mean diameters of the prepared microcapsules were $\sim 50$ (A) and 100 (B) $\mu \mathrm{m}$.

\subsection{The effects of healing temperature on the fracture behaviour}

The control experiments of epoxy without microcapsules show no healing effects, in agreement with our results reported by Yuan et al. [14]. Figure 4 shows curves of the fracture load with extension at the compressive direction for the samples under different healing temperatures at 18,55 and $110^{\circ} \mathrm{C}$ lasting $17 \mathrm{hrs}$. They clearly show that the maximum fracture loads at 55 and $110^{\circ} \mathrm{C}$ are higher than at $18^{\circ} \mathrm{C}$. At $\sim 55^{\circ} \mathrm{C}$ it shows the highest fracture load.

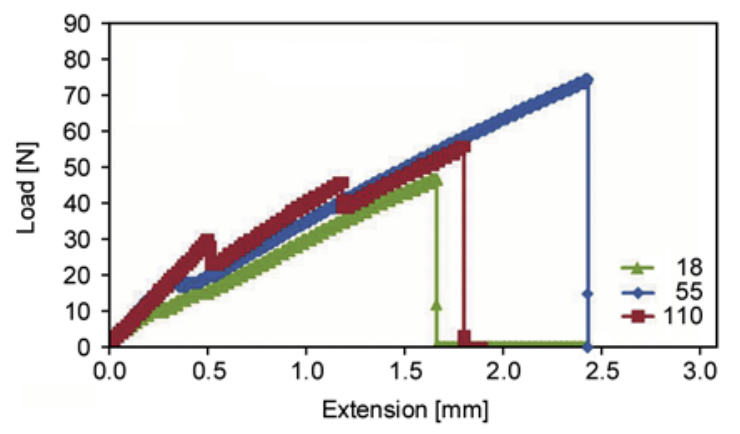

Figure 4. Load-extension curves of epoxy samples under different healing temperatures ( $L$ to $R: 18,110$ and $55^{\circ} \mathrm{C}$ )

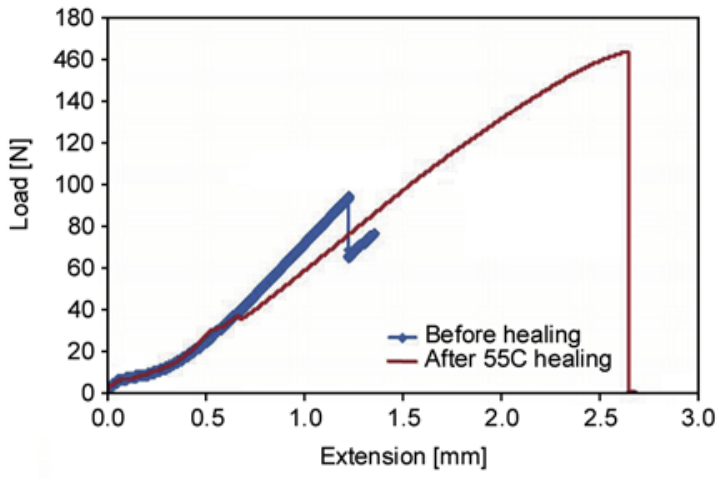

Figure 5. The load-extension curves before and after $55^{\circ} \mathrm{C}$ healing

The load-extension curves show in a zigzag way, especially at a higher temperature $110^{\circ} \mathrm{C}$, which may be explained by the difference of polymerization and heat stability of the self-healing crosslinkers. The rapid crack growth takes place after the maximum load. Figure 5 shows load-extension curves before and after $55^{\circ} \mathrm{C}$ healing. The maximum fracture loads increase significantly after $55^{\circ} \mathrm{C}$ healing. The virgin sample loads nonlinearly followed by a linear regime to $95 \mathrm{~N}$. This is followed by a drop in load (virgin slope failed and crack initiated) and a second linear regime until the crack length (not extension) to $\sim 2 \mathrm{~mm}$ length, which suggests that the crack has propagated in the material. The crack of virgin sample retains some load-bearing capability, however the load of crack initiation is higher than the load of propagation in the material. The healed sample loads non-linearly followed by a linear regime to around $\sim 30 \mathrm{~N}$ followed by a minor zigzag regime without a clear crack initiation and loading until the sample would have a same crack length, however the rapid crack growth happens at a $165 \mathrm{~N}$ load (crack-length independent).

The healing efficiency values of the microcapsulesloaded epoxy samples healing lasting for $17 \mathrm{hrs}$ at different temperatures are shown in Figure 6. The healing efficiency values are determined by comparing the healed peak loads to the virgin peak loads. The average self-healing efficiency at healing temperature 18,55 and $110^{\circ} \mathrm{C}$ for $17 \mathrm{hrs}$ is 93 , 171 and $158 \%$. The given values are mean values of three parallel tests. It is obvious that the self-healing efficiency of the microcapsule-loaded epoxy/ mercaptan-derivative samples is significantly higher under healing temperature at $\sim 55^{\circ} \mathrm{C}$. This result is 


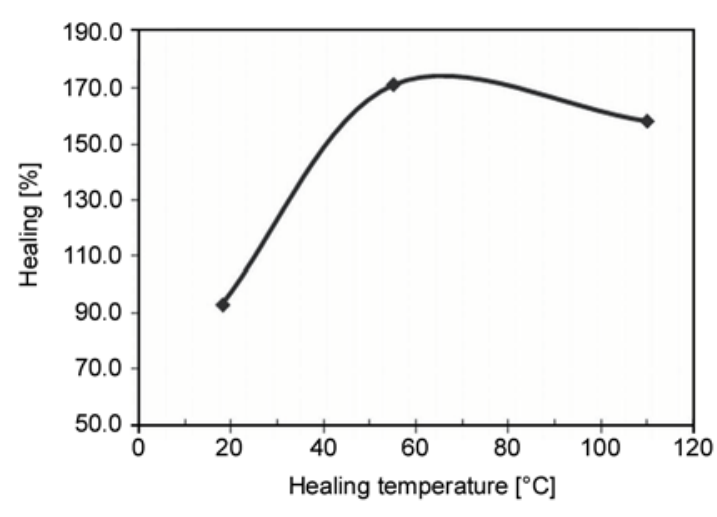

Figure 6. The self-healing efficiency of microcapsulesloaded epoxy samples with a healing temperature

in accordance with the DSC result which shows the healing peak temperature $56.53^{\circ} \mathrm{C}$ of microcapsules.

\subsection{FTIR and DSC}

The microcapsule-loaded epoxy samples under different healing temperatures at 18,55 and $110^{\circ} \mathrm{C}$ were investigated by FTIR spectra. The absorption peaks at 2800-3200, 2300-2400 and 1500$1800 \mathrm{~cm}^{-1}$ are attributed to $\mathrm{C}-\mathrm{H}, \mathrm{CO}_{2}$ and carbon double bond absorption bands respectively. Figure 7

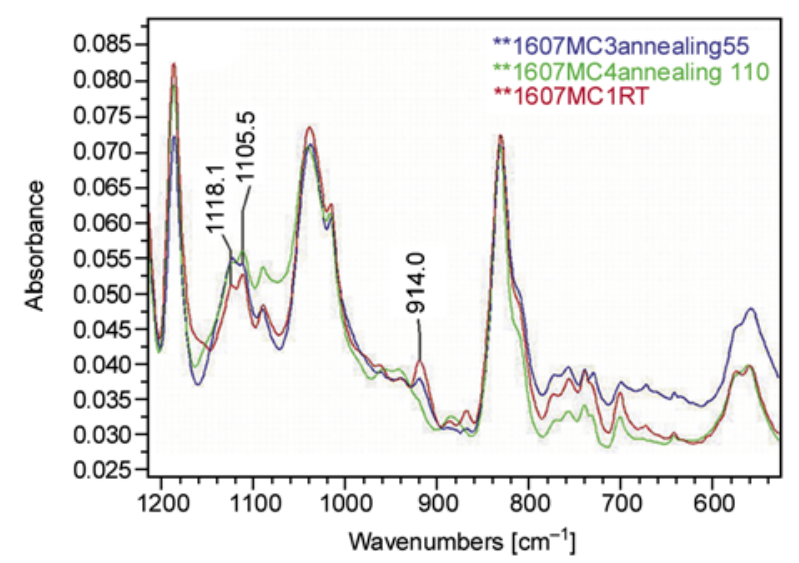

Figure 7. Expanded FTIR spectra between 1200 and $500 \mathrm{~cm}^{-1}$

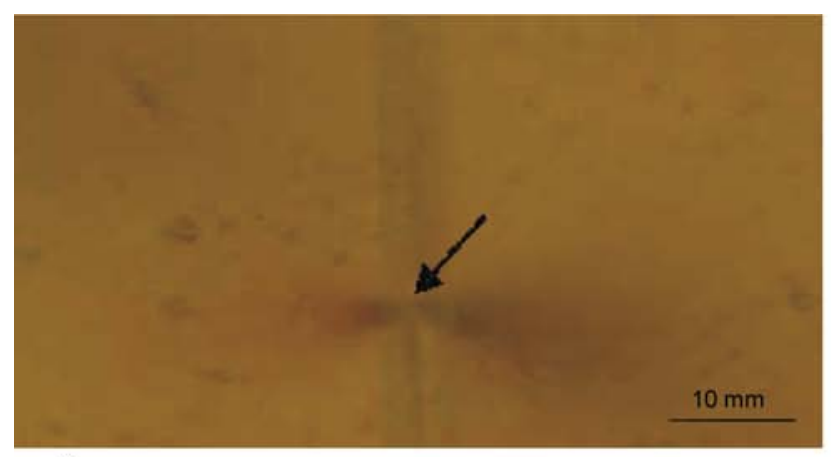

a)

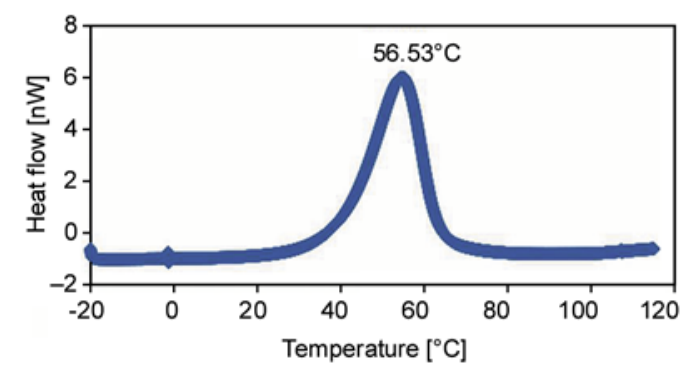

Figure 8. DSC curve of the epoxy and hardener-loaded microcapsules mixture

shows expanded FTIR spectra between 1200 and $500 \mathrm{~cm}^{-1}$. The peaks at 1118 and $1105 \mathrm{~cm}^{-1}$ correspond to $\mathrm{C}-\mathrm{O}$ stretch. The stretch mode of the oxirane ring of the epoxy group appears at $914 \mathrm{~cm}^{-1}$. This disappears with increasing temperature probably due to the curing of epoxy at a higher temperature.

Figure 8 shows DSC curves of the epoxy and hardener-loaded microcapsules mixture. The exothermic reaction peak at $56.53^{\circ} \mathrm{C}$ with onset temperature $41.77^{\circ} \mathrm{C}$ is the curing temperatures of the epoxy and hardener-loaded microcapsules. It is in accordance with the results obtained by the above test results which show that the fracture load and healing efficiency values of the microcapsuleloaded epoxy/mercaptan-derivative samples are significantly higher under healing temperature at $\sim 55^{\circ} \mathrm{C}$.

\subsection{Fracture morphology and photo elasticity}

Using a polariscope, the specimens that were cracked (a) or healed (b) under stress are shown in Figure 9. Figure 9a shows the end of the crack in specimen with birefringence. Figure $9 b$ shows the healed crack without birefringence.

The images in Figure 10 show a typical crack surface for a microcapsule specimen at 18 and $55^{\circ} \mathrm{C}$. With regard to the microcapsule specimen, it is vis-

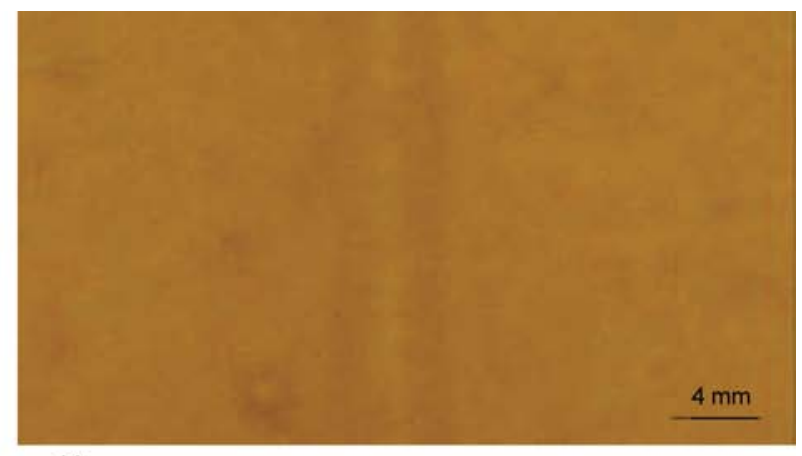

b)

Figure 9. Photoelastic stress distribution of cracked a) and healed b) samples 


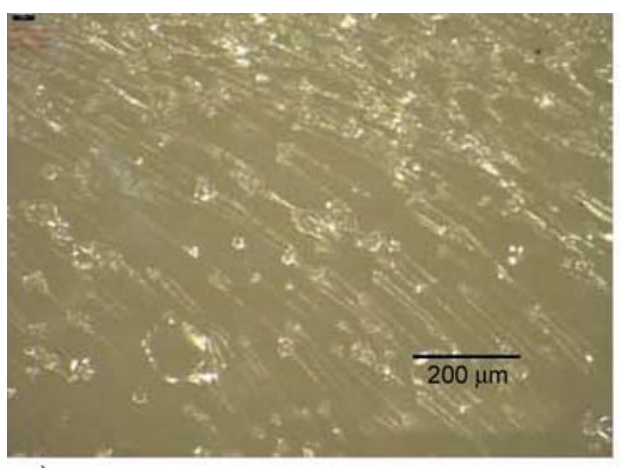

a)

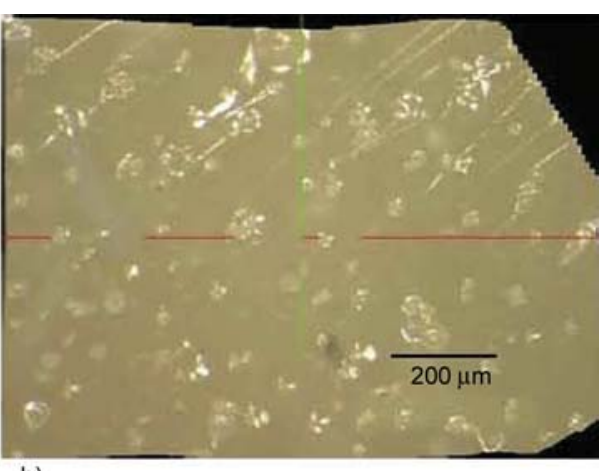

b)

Figure 10. Optical images of fractured microcapsules-loaded epoxy cured at $18^{\circ} \mathrm{C}$ a) and $55^{\circ} \mathrm{C} \mathrm{b}$ )

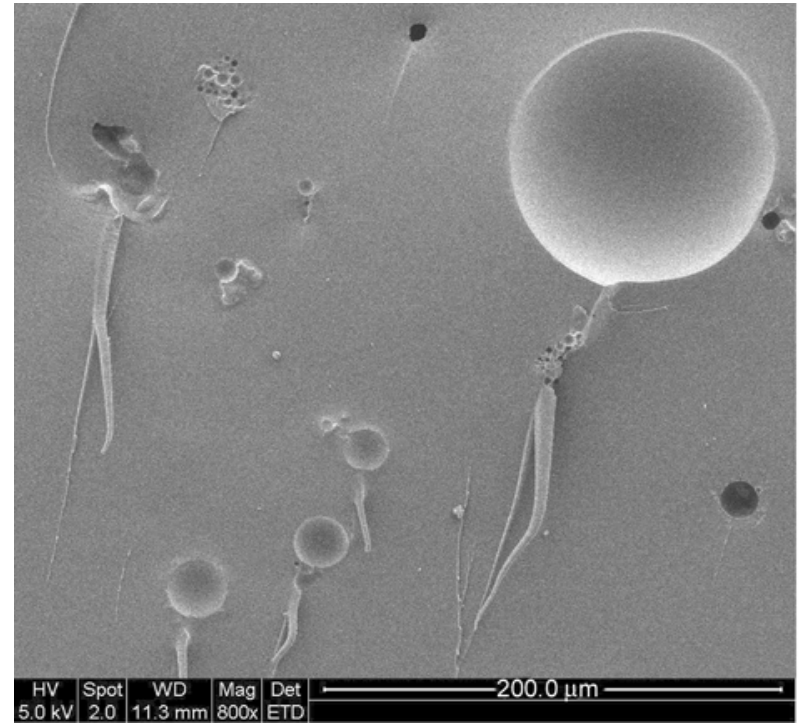

Figure 11. SEM micrograph of fractured microcapsulesloaded epoxy

ible that the healants of fractured microcapsules have flowed out to the fracture surface so that they can react and heal the cracks at a suitable temperature. The SEM image in Figure 11 also clearly shows the micro-cracking pinning from the fractured microcapsules. The subsurface micro-crack pinning on the fracture plane (Figure 11) may contribute to additional energy consumed in the course of fracture $[14,17]$.

\subsection{Discussion}

It has been reported that for PMF microcapsules containing DCPD applied to polymeric composites, the higher self-healing efficiency can be obtained by adding a lower content of microcapsules with larger diameter or by adding a higher content of microcapsules with smaller diameter, and increasing microcapsule diameter can improve the maximum self-healing efficiency [13]. Although microcapsules don't behave like hard solid particles, similar fracture behavior has been in rubber toughened epoxy [17]. The deformation and subsurface micro-cracking associated with rubber toughened epoxy are similar to the mechanisms identified for microcapsule toughened epoxy. Previous reports $[14,17,18]$ which have achieved over $100 \%$ healing have suggested that such high efficiency healing is the results of crack deviation or pinning from the original damage line or healing of the material past the original pre-crack using the higher fracture toughness of repair binder than that of the bulk material.

The fracture behavior of microcapsules-loaded epoxy matrix was investigated using a double torsion test which is based on a Mode I (opening) loading. The typical virgin sample loads nonlinearly followed by a linear regime. This is followed by a drop in load (virgin slope failed and crack initiated) and a second linear regime with a crack development. The healed sample loads non-linearly followed by a linear regime, then zigzag regime without a clear crack initiation and loading linearly until the rapid crack growth happens. Clearly microencapsulated epoxy and mercaptan-derivative healing agents can have the capability to heal the cracks after damage, but also provides the damaged sites with a higher fracture load. Here a higher selfhealing efficiency can be achieved by choosing a suitable curing temperature. The healing efficiency increases, then decreases with a healing temperature. The best healing temperature at about $55^{\circ} \mathrm{C}$ curing temperature of microencapsulated epoxy and mercaptan-derivative with healing efficiency $171 \%$ is determined by the fracture test and DSC measurement. The increased fracture load is correlated with a healant release and curing. The subsurface micro-crack pinning or deviation on the fracture 
plane and a stronger microencapsulated epoxy and mercaptan-derivative binder than that of the bulk epoxy along the original pre-crack may contribute to additional energy consumed in the course of fracture, leading to a greater than $100 \%$ self-healing efficiency. The reduced performance after higher temperature annealing at $120^{\circ} \mathrm{C}$ may be mainly due to thermal degradation of additional self-healing microcapsules. Based on our previous test results, the Epoxy/Mercaptan-derivative microcapsules provide two independent effects: increase the load carrying capacity of the epoxy from general toughing after healing and the ability to self-heal the virgin fracture at room temperature.

\section{Conclusions}

The fracture behavior of microcapsule-loaded epoxy matrix is studied for the effects of temperature. The load-extension curves start non-linearly followed by a linear regime, then zigzag regime and a linear regime until fails. The microencapsulated epoxy and mercaptan-derivative healing agents have flowed out to the fracture surface of epoxy so that they can react and heal the cracks. The addition of microcapsules appears to significantly increase the load carrying capacity of the epoxy after healing. The healing efficiency increases, then decreases with the healing temperature. The best healing temperature is at the about $55^{\circ} \mathrm{C}$ curing temperature of microencapsulated epoxy and mercaptan-derivative with healing efficiency up to self-healing efficiency $171 \%$. Heating the polymer samples after fracture will change the mechanical properties, resulting in changes in the fracture strength due to the self-healing microcapsules or thermal degradation on polymers. It shows that the suitable healing temperature has a great effect on healing, thereby influencing the fracture behavior. The subsurface micro-crack pinning or deviation on the fracture plane and a stronger microencapsulated epoxy and mercaptanderivative binder than that of the bulk epoxy may lead to a greater than $100 \%$ self-healing efficiency. The Epoxy/Mercaptan-derivative microcapsules provide two independent effects: the capability to recover their load transferring ability after fracture and the ability to self-heal the virgin fracture at room temperature.

\section{Acknowledgements}

This work was supported by Foundation for Research, Science and Technology for New Zealand Science \& Technology Post Doctoral Fellowship. Thanks also go to the lab staff at CACM, Associate Professor Allan Easteal and Ms Michel Nieuwoudt, Department of Chemistry, the University of Auckland, New Zealand.

\section{References}

[1] Murphy E. B., Wudl F.: The world of smart healable materials. Progress in Polymer Science, 35, 223-251 (2010).

DOI: $10.1016 /$ j.progpolymsci.2009.10.006

[2] Yuan Y. C., Yin T., Rong M. Z., Zhang M. Q.: Self healing in polymers and polymer composites. Concepts, realization and outlook: A review. Express Polymer Letters, 2, 238-250 (2008).

DOI: 10.3144/expresspolymlett.2008.29

[3] White S. R., Sottos N. R., Geubelle P. H., Moore J. S., Kessler M. R., Sriram S. R., Brown E. N., Viswanathan S.: Autonomic healing of polymer composites. Nature, 409, 794-797 (2001). DOI: $10.1038 / 35057232$

[4] Kessler M. R., Sottos N. R., White S. R.: Self-healing structural composite materials. Composites Part A: Applied Science and Manufacturing, 34, 743-753 (2003).

DOI: $10.1016 / \mathrm{S} 1359-835 X(03) 00138-6$

[5] Brown E., Sottos N., White S.: Fracture testing of a self-healing polymer composite. Experimental Mechanics, 42, 372-379 (2002).

DOI: $10.1007 / \mathrm{BF} 02412141$

[6] Cho S. H., Andersson H. M., White S. R., Sottos N. R., Braun P. V.: Polydimethylsiloxane-based self-healing materials. Advanced Materials, 18, 997-1000 (2006). DOI: $10.1002 / \mathrm{adma} .200501814$

[7] Caruso M. M., Blaiszik B. J., White S. R., Sottos N. R., Moore J. S.: Full recovery of fracture toughness using a nontoxic solvent-based self-healing system. Advanced Functional Materials, 18, 1898-1904 (2008). DOI: $10.1002 / \mathrm{adfm} .200800300$

[8] Jinglei Y., Keller M. W., Moore J. S., White S. R., Sottos N. R.: Microencapsulation of isocyanates for selfhealing polymers. Macromolecules, 41, 9650-9655 (2008).

DOI: $10.1021 / \mathrm{ma} 801718 \mathrm{v}$

[9] Brown E., White S., Sottos N.: Fatigue crack propagation in microcapsule-toughened epoxy. Journal of Materials Science, 41, 6266-6273 (2006). DOI: $10.1007 / \mathrm{s} 10853-006-0512-\mathrm{y}$

[10] Karger-Kocsis J., Friedrich K.: Microstructure-related fracture toughness and fatigue crack growth behaviour in toughened, anhydride-cured epoxy resins. Composites Science and Technology, 48, 263-272 (1993). DOI: $10.1016 / 0266-3538(93) 90143-5$ 
[11] Nagasawa M., Kinuhata H., Koizuka H., Miyamoto K., Tanaka T., Kishimoto H., Koike T.: Mechanical fatigue of epoxy resin. Journal of Materials Science, 30, 1266-1272 (1995).

DOI: 10.1007/BF00356129

[12] Kamphaus J. M., Rule J. D., Moore J. S., Sottos N. R., White S. R.: A new self-healing epoxy with tungsten (VI) chloride catalyst. Journal of the Royal Society: Interface, 5, 95-103 (2008).

DOI: $10.1098 /$ rsif.2007.1071

[13] Li Y., Liang G-Z., Xie J-Q., He S-B.: Synthesis and characterization of microencapsulated dicyclopentadiene with melamine-formaldehyde resins. Colloid and Polymer Science, 285, 781-791 (2007).

DOI: $10.1007 / \mathrm{s} 00396-006-1621-5$

[14] Yuan Y. C., Rong M. Z., Zhang M. Q., Chen J., Yang G. C., Li X. M.: Self-healing polymeric materials using epoxy/mercaptan as the healant. Macromolecules, 41, 5197-5202 (2008).

DOI: $10.1021 / \mathrm{ma} 800028 \mathrm{~d}$
[15]Yuan L., Liang G., Xie J., Li L., Guo J.: Preparation and characterization of poly(urea-formaldehyde) microcapsules filled with epoxy resins. Polymer, 47, 5338-5349 (2006).

DOI: 10.1016/j.polymer.2006.05.051

[16] Dobetti L., Pantaleo V.: Application of a hydrodynamic model to microencapsulation by coacervation. Journal of Microencapsulation, 19, 139-151 (2002). DOI: 10.1080/02652040110055199

[17] Brown E. N., White S. R., Sottos N. R.: Microcapsule induced toughening in a self-healing polymer composite. Journal of Materials Science, 39, 1703-1710 (2004).

DOI: 10.1023/B:JMSC.0000016173.73733.dc

[18] Yin T., Rong M. Z., Zhang M. Q., Yang G. C.: Selfhealing epoxy composites - Preparation and effect of the healant consisting of microencapsulated epoxy and latent curing agent. Composites Science and Technology, 67, 201-212 (2007).

DOI: $10.1016 /$ j.compscitech.2006.07.028 